\title{
ENGINEERING ACTIVITIES IN RUSSIAN UNIVERSITIES
}

\author{
Romanovich L.G. \\ Belgorod state technological University named after \\ V. G. Shukhov \\ Belgorod, Russia \\ bel31rm@yandex.ru \\ Romanovich M.A. \\ Belgorod state technological University named after \\ V. G. Shukhov \\ Belgorod, Russia
}

\author{
Deryabina S.A. \\ Peoples Friendship University of Russia \\ Moscow, Russia
}

\begin{abstract}
The development of engineering centers at the universities is a very important challenge for the Russian innovation system and the economy as a whole.

Due to the specifics of its activities, engineering centers, on the one hand, are an important part of the technological chain of creating competitive products in certain sectors, and on the other - perform the functions of direct agents of modernization, eliminating the existing infrastructure "failures" in the innovation cycle.
\end{abstract}

The authors pay special attention to the consideration of basic concepts in the field of engineering and the problems associated with the lack of the concept of engineering in the Russian Federal legislation, which hinders the development of engineering activities on the basis of universities.

The authors analyzed the methodological approaches to the engineering of foreign countries and formulated recommendations aimed at improving the mechanism of stimulating engineering activities on the basis of universities. center

Keywords - engineering, engineering activity, engineering

\section{INTRODUCTION}

The crisis phenomena typical for the economies of many countries of the world have had a tangible impact on the processes of innovative development of the global economy. The enthusiasm and willingness of companies to actively invest in any high-tech project or new product has decreased. Business has become more cautious and prudent. However, accelerating the pace of development of science has forced the company to think about what they will be able to offer its customers tomorrow.

In addition, any innovative product promises a large rate of return, which makes business take risks and invest in new technologies and developments. Russia is still in a catch-up position, and to get closer to the world's technological leaders, it is necessary to establish a close relationship between science and business as soon as possible [1].

To do this, it is necessary to create an effective and effective innovation infrastructure that will become a driver of development of all industries - both new and traditional. In the developed countries, engineering provides a link between science and production. In Russia, it is in its infancy - the volume of the industrial engineering market in the United States is 21 times more than in Russia.

At the same time, in recent years, the country is actively beginning to create engineering centers focused on innovative industries. In particular, the Ministry of industry and trade offers to open them at the leading technical universities of the country and on the basis of industrial production. It is planned to pay salaries to students who will work there or have an internship. Such measures will ensure a symbiosis of science and technology, as well as help enterprises in the staffing of young qualified personnel.

It is preferable to create centers on the basis of the country's leading technical universities, as well as enterprises themselves, which have the appropriate design and technological competencies. When we choose the profiles of engineering centers, it is necessary to take into account the real needs of industrial enterprises operating in a particular region [2].

Thus, in modern conditions, the research topic is particularly relevant and has an important practical significance. The activity of engineering organizations, which requires a high degree of professionalism in the field of design, design and project management, is also a catalyst for the demand for training of engineering personnel, demanded by the Russian industry. 


\section{BASIC PART}

In the recent years, the state has paid serious attention to increasing investment in the Russian economy. In modern conditions, when a potential investor is pressured by "negative" forecasts of some rating agencies, the relevance of creating a favorable climate for investment reaches a new level. What is the guide of a foreign entrepreneur, when he makes a decision on the choice of the region?

First of all, the assessments of independent experts on the effectiveness of investments. The criteria for this assessment, in particular, are the regional legislation, the availability of resources, the clarity of gas and electricity tariffs, the availability of infrastructure, and human resources.

But the investor needs not less reliable Russian partners who can contribute to the implementation of his project, in particular, within the framework of localization of documentation necessary for the construction of production facilities. Here, it is important for the investor to find an engineering company with experience in implementing large projects that would fulfill the design and working documentation for construction, taking into account the requirements of Russian rules and regulations.

Due to the sharp drop in the volume of construction of large industrial and energy facilities over the past twenty in Russia there was no experience in the design and construction of such facilities, not implemented the practice of integrated engineering, which in turn naturally led to a decrease in the quality of construction, increase in terms and cost of investment projects.

The results of the study showed that if foreign players have long practiced such approach as EPCM-contracts (Engineering Procurement and Construction Management - engineering, supply and construction management), in which the contractor fully concentrates on the processes of design, consulting, procurement and contracts; the Russian companies are just beginning to master it.

At the same time, it is obvious that in modern conditions in economically developed countries a highly competitive market of engineering services has been formed on the basis of universities $[3,4]$ and the real sector of the economy $[5,6,7]$.

So, only in the US today there are 142 thousand companies, the largest of them occupy no more than $5 \%$ of the market. In Russia, however, is dominated by up to a hundred large engineering companies. And two of them ("Stroygazconsulting" and "Stroygazmontazh") consolidate almost $40 \%$ of the market in monetary terms.

This is due to the fact that at the present stage most of the demand is large-scale capital-intensive projects of the state and state companies, which can be performed only by large engineering companies. The largest customer companies prefer a narrow circle of affiliated engineering structures, which reduces the level of competition. And medium and small customers lack their own funds and problems with borrowed capital. Therefore, the segment of small and medium-sized engineering companies is poorly developed. As a rule, these are regional players specializing in the maintenance of housing and utilities and power grid complex.

In Russia, more than $70 \%$ of the revenue of engineering companies is generated by the oil and gas sector. But this is mainly low-tech work-the construction of oil and gas pipelines and related infrastructure. Therefore, the degree of innovative development of the fuel and energy complex is low, despite the rather large amounts of investment.

Another $26 \%$ of the market falls on the power industry, where demand is caused by the obligations of energy companies to the state to upgrade capacities. This is a clear example of how administrative measures can stimulate the market.

Other sectors (construction, metallurgy and mining, chemical sector, engineering) use little engineering services, which calls into question the pace of their development. In terms of technology, the situation in the domestic engineering does not correspond to modern global trends.

In Russia, engineering is understood as the installation of equipment and its commissioning. While in technologically more developed countries, "advanced" engineering is practiced, covering the entire design process and taking into account the product life cycle [2, 4].

National engineering cannot yet respond to the current scientific and technological challenges. Many engineering centers do not have information about current technologies, methods of design and construction of industrial facilities. In addition, there is a lack of experience and knowledge for the implementation of turnkey contracts.

The concept of "engineering services" in our country has appeared relatively recently, which is associated with the development of market relations. And its entry into the native lexicon is due to actively developing international relations and entrepreneurship.

American Council of engineers for professional development (CPD) gives the following definition. "Engineering" is the creative application of scientific principles to the design or development of structures, machines, equipment, manufacturing processes, or the work of using them alone or in combination; the construction or management of the same with full knowledge of their design; the prediction of their behavior in certain operating conditions; all this in accordance with the expected functionality, efficiency of operations or safety of life and property [7]

The results of the analysis showed that at present the term "engineering" has entered the professional dictionary of Russian specialists and is at the stage of introduction into the legal turnover.

So, from the point of view of the national chamber of engineers of Russia: engineering is actually the design. According to the preliminary assessment [8], engineering for $80-90 \%$ consists of design work: preparation together with the customer of technical specifications, pre-investment research, development of project documentation, development of working documentation. 
The remaining $10-20 \%$ are the functions of the project designer: collection of initial data and surveys, supervision, selection of equipment, preparation of technological regulations, participation in commissioning, preparation of documentation "how to build", commissioning, training of customer personnel. There is no unambiguous definition of engineering in the Russian legal framework.

On the one hand, this can be explained by the lack of attention of legislators to this type of organizations, and on the other - the complexity of standardization of activities, the heterogeneity of which is due to differences in business practices in this sector of the economy.

In the draft of the Federal Law "On engineering activities in the Russian Federation», engineering (engineering services) is proposed to understand as the type of activity of professional engineers to perform engineering (engineering) activities on a commercial basis [9].

The analysis of the publications shows the organization of modern international regulatory and methodological framework in the field of engineering. Leading positions are taken by France, England, Japan, Germany, which have the relevant legislation in the field of engineering.

Thus, the UN economic Commission for Europe has developed a "Guide to the preparation of international engineering contracts", "Guide to the preparation of international contracts of the consortium", etc.

Guidelines and regulations in the field of engineering were also developed by national associations of engineers, in particular American and English.

There are different classifications of forms of engineering.

The engineering classification given by the UN economic Commission for Europe [10] and adopted by the engineering business community, distinguishes 5 types (table 1.).

TABLE I. CLASSIFICATION OF FORMS OF ENGINEERING ACTIVITIES ACCORDING TO THE UN ECONOMIC COMMISSION FOR EUROPE

\begin{tabular}{|l|l|}
\hline \multicolumn{1}{|c|}{ Engineering } & \multicolumn{1}{|c|}{ Maintenance } \\
\hline Consultative & $\begin{array}{l}\text { Technical design, supervision, planning and } \\
\text { construction (CPD, networks), monitoring of } \\
\text { construction works (technical supervision), } \\
\text { testing, examination, consulting }\end{array}$ \\
\hline Technological & $\begin{array}{l}\text { Provision of technologies for construction } \\
\text { and operation of facilities, transfer of } \\
\text { licenses, production experience }\end{array}$ \\
\hline $\begin{array}{l}\text { Constructive or } \\
\text { general }\end{array}$ & $\begin{array}{l}\text { Design, supply and installation of the } \\
\text { equipment }\end{array}$ \\
\hline Integrated & $\begin{array}{l}\text { Design, supply of equipment, CDP } \\
\text { management and turnkey commissioning of } \\
\text { the facility }\end{array}$ \\
\hline $\begin{array}{l}\text { Technical } \\
\text { assistance }\end{array}$ & $\begin{array}{l}\text { A service or a number of services provided } \\
\text { after its completion for the development of } \\
\text { technologies, equipment, supervision and } \\
\text { training of personnel }\end{array}$ \\
\hline Source: United Nations Convention on contracts for the international sale of goods
\end{tabular}

The most common are consultative, constructive, technological and integrated engineering, which includes many of the functions of the above types: design, supply of equipment, management of construction and installation works (SMR) and the delivery of the industrial facility "turnkey".

In foreign practice, the company often provides services for the organization of financing (attraction of additional investments), management of supply of material and technical resources and performance of construction and installation works, as well as the commissioning of the built facility.

Based on the classification of engineering given by the UN economic Commission for Europe, the most typical for the Russian practice is consultative engineering related to predesign studies, design of construction objects and implementation of designer supervision [10].

At the same time, technological engineering (process engineering), consisting of providing the customer with technologies (including the transfer of technologies, patents, production experience and knowledge, as well as training and supervision of the use of technology), is relatively poorly developed. Not widely used is constructive or general engineering, covering not only the design and supervision, but the supply of equipment and its installation. A number of authors in their works [10,11] distinguish financial engineering, describing it as "the youngest and still insufficiently studied area, changing mainly the quality of production and supply of financial services", and point to the relevance and importance of the development of this new direction.

The essence of financial engineering is to create new financial products and services that are used by financial institutions in the allocation of resources, risks, liquidity, income and information in accordance with the financial needs of customers and changes in the macro - and microeconomic situation. In the draft of the Federal Law "On engineering activities in the Russian Federation», only 3 types of engineering are allocated: constructive engineering, product engineering, engineering and consulting services [6]:

1. Construction engineering is an engineering activities in the investment and construction sector to create the information necessary to achieve the objectives of investment by creating and changing real estate, including the modeling of technological processes, design of buildings and structures, preparation, provision and technical support of construction processes, supervision of construction, installation, commissioning, pilot operation of industrial and economic facilities and other, inextricably linked to these tasks, engineering activities.

2. Product engineering is the engineering activity in the industrial sphere to create the information necessary to achieve the objectives of investment by creating and changing movable products, including consumer goods, industrial products, equipment, tools, machines and mechanisms, building materials and structures, vehicles and special equipment and other engineering activities, inextricably associated with the creation of such products.

3. Engineering consulting services - a specialized type of engineering services, including consulting the investor, the customer, the technical customer to perform one or more stages of the project. 
Taking into account the underdeveloped system of technological engineering in Russia at the present stage and the most urgent problem of effective transfer of technologies, security documents and licenses, production experience and knowledge, as well as the problem of personnel training and supervision of the use of technologies, we consider it appropriate and important to distinguish technological engineering among its types in the draft law and to determine it as a priority direction for the development of engineering at universities.

For universities, the creation of an engineering center is one of the most effective forms of commercializing scientific and technical results, as well as for founding companies that provide access to competitive advantages for using new technologies.

Engineering centers on the basis of universities are engaged in the implementation of applied research, preparation of feasibility studies of planned investments, planning, and training. An important element of the engineering centers is the design activity-design, creation and testing of prototypes of technical devices, preparation of design documentation. A key element for the commercialization of engineering centers is production activities aimed at the introduction of technologies into the production chains of the real sector and their further support [4].

Among the benefits expected from the creation of engineering centers for universities, we can distinguish:

- commercialization of research results, equipment obtained earlier by the University;

- additional income;

- formation of practical competencies of students through their participation in real projects;

- employment of students and graduates.

For the real economy, the benefits are:

- improving the efficiency of activities through the introduction of advanced developments;

- growth of supply in the engineering market;

- use of the infrastructure of universities and research organizations for research and development of applied research.

Since 2014, Russia has a program "Development of engineering and industrial design", which is supervised by the Ministry of Industry and Trade of the Russian Federation. The idea to involve as many organizations in engineering activities and is aimed at creating new channels of communication between fundamental science and production. Time of the program - 2014-2018. The total volume of budget financing is planned at the level of 3 billion rubles [12]. One of the subprograms includes a key provision - stimulating the creation and development of engineering centers on the basis of educational organizations.
Selection of pilot projects of engineering centers on the basis of universities is conducted during an open competition, under the auspices of the Ministry of Education and Science. Annually, the Ministry of Education and Science of the Russian Federation holds open public competitions for the provision of state support for pilot projects for the development of engineering centers on the basis of universities.

State support to projects is provided in the form of granting a subsidy from the federal budget to provide financial support for the execution of the state task in order to implement the development program of the innovation centers, created on the basis of the university.

The competition is held from 2013, the competition in it is quite high - from 50 to 60 projects admitted before the competition, and only 10 of them are received support. According to the Roadmap for the development of engineering in Russia from 2014 to 2018, 95 engineering centers should be established on the basis of educational organizations of higher education and scientific organizations.

The state support of the selected projects is carried out by granting subsidies from the federal budget to higher educational institutions selected according to the results of the competitive selection to refund the costs of their implementation.

The subsidy is granted for 2 years (2017-2018), the reporting period for the project is 5 years. The volume of the requested subsidy should be calculated for a period of 1 to 2 years beginning in 2017 and should not exceed:

- in 2017 - 40 million rubles;

- in 2018 - 60 million rubles.

Despite the obvious advantages and benefits of setting up engineering centers, the organization of their activities remains insufficiently researched. Thus, experts $[13,14]$ note the lack of a common understanding of the economic nature of engineering services and the specifics of interaction between engineering centers and clients.

However, the analysis of innovation activity in Russia shows insufficiency of the taken measures compared to foreign countries for replacing sectoral research institutes by universities.

Concerning the commercialization of the results of scientific and technological activities, for example, in the format of R \& D for industrial companies, Russian universities face a number of problems, among which, in the opinion of experts [15], in terms of significance, we can distinguish the following:

- Lack of sectoral pilot production: it is necessary to refine the university development to the prototype and serial model, as well as for adequate training of the engineer and scientist of his specialty.

- Asymmetry of information: business representatives do not know the scientific and technological capabilities of 
universities, and universities have a poor understanding of the needs of companies.

- Inconsistency of the university's position with the ordered services: due to the fact that business is generally not interested in fundamental developments, most of the services ordered are related to the finalization of the already existing technology / product at the enterprise. To solve such problems, the university needs to be highly integrated into the enterprise's activities, an understanding of industry specificity and knowledge of the supplier market.

Long term decision-making: due to mutual misunderstanding and overstated expectations, the decisionmaking processes are delayed and project deadlines are often violated.

The subject of engineering in Russia is becoming a key for the further development of the industry, the introduction of new product samples to the market, as well as integration into international projects, chains and markets. In other words, having our own engineering is a key element of the global competitiveness of Russian manufacturers.

We believe that cooperation with domestic designers is mutually beneficial for all parties. Design and engineering companies receive additional profits, regions-producers-the multiplier effect of the implementation of major projects: employment, taxes, territorial development, the growth of skills. Cooperation with recognized leaders in the field of engineering and industrial construction enriches domestic engineering with international experience and provides access to advanced technologies, which can be further broadcast to other companies and regions of the country.

\section{CONCLUSION}

Thus, analyzing the problems of modern development of engineering activities, approaches to basic concepts, we believe it is advisable to pay attention to the following provisions:

1. Engineering is a powerful tool for improving business efficiency through the provision of intelligent services of design, calculation and analytical, production nature.

2. In contrast to the international methodological approach to the concept of engineering and its classification, the proposed activities in the Draft Federal Law "on engineering (engineering) in the Russian Federation" types of engineering do not contain technological engineering, either as a separate type of engineering or as clearly defined elements.

3. In the considered Draft Federal Law, it is advisable to identify technological engineering as a strategically important type in the context of the development of the innovative economy, as well as to determine the priority direction of its development on the basis of universities.

4. Engineering is a bridge between science and technology. Organizing engineering centers on the basis of universities, it is advisable:

- to combine the potential of modern achievements of Russian science and positive experiences of foreign engineering. The symbiosis of universities with the real sector of the economy will reduce the dependence on imported technologies;

- to involve students, postgraduates, doctoral students of technical universities, as well as graduates in the work of engineering centers, which will allow one to activate innovative processes on the basis of universities and the introduction of research results in the real economy.

\section{Acknowledgment}

The work has been carried out in the framework of the program of development of the flagship university on the basis of BSTU named after V.G. Shukhov.

\section{References}

[1] L. Romanovich, V. Sevostyanov, M. Romanovich, M. Sevostyanov, A. Arkatov "Innovation activity and technology transfer of higher education” Journal of Applied Engineering Science, 2014, v. 12, № 4, p. 273-276.

[2] D.V. Manturov "Engineering Development is the most importan component of the formation of innovative economy in Russia" Bulletin of Moscow State Technical University. N. Uh. Bauman. Series "Mechanical Engineering", № 2 (91), 2013.

[3] M.V. Sevostyanov, L.G. Romanovich, V.S. Sevostyanov, I.G. Martakov "Multifunction technological complexes - the basis of innovative development and personnel training of Russian higher school" International Journal of Pharmacy and Technology, v. 8. № 4, 2016, p. 25071-25077.

[4] L.G. Romanovich, E.I. Evtushenko, M.A. Romanovich, D.V. Kudinov "Innovation activity and business incubators based on institutio of higher education. the experience of Russia" Journal of applied engineering science, v. 13. № 3, 2015, p. 161-166.

[5] I. Chekmarev, E. Yoda "Engineering center as an element of innovative infrastructure of the region" Social and economic phenomena and processes, No. 9, 2014

[6] V. A. Arslanov, I. S. Gazizov, N. F. Kashapov "Engineering centers as a factor of entering the region into global production cooperation" Bulletin of Economics, law and sociology, №4, 2014.

[7] I. V. Mesherin, "Engineering is a design [Electronic resource: the official website of the national chamber of engineers]" Access mode: http://npirf.ru/inzhiniring-eto-proektirovanie

[8] "Electronic portal of the Ministry of industry and trade of Russia" Access mode: http://minpromtorg.gov.ru/press-centre/news/\#!8837

[9] Draft of the Federal Law "On engineering (engineering) activities in the Russian Federation" Access mode: http://npirf.ru/inzhiniring-etoproektirovanie

[10] K. S. Litvinov "Modern market of engineering services" Russian foreign economic Bulletin, No. 5, 2010, p. 69

[11] V. V. Kondratiev, V. J. Lorenz "Give engineering! (Navigator for the professional)”, M.: Eksmo, 2007, p. 576.

[12] E.A. Savyonenok "University and business: "Two pairs in a boot", In: Entrepreneurial University and the possibilities of the development of the region: international experience and the Russian context. Moscow: Non-profit organization Foundation "New Eurasia", 2012, p. 133-138.

[13] E.B. Kolbachev "Economic management of consulting engineering" Drukerovsky Vestnik, 2016, No. 2, p.111-119,

[14] M.A. Gershman, L.M. Gokhberg, I.A. Kuznetsova "Statistica monitoring of the market of engineering services and industrial design" Nat. Issled. University Higher School of Economics, Moscow: NIU HSE, 2016, p.14.

[15] R. Tassabehji, A. Isherwood, "Management Use of Strategic Tools for Innovating During Turbulent Times", Strategic Change, 23 (1-2), 2014 , p.63-80. 
